\title{
Diversidad de bacterias cultivables con capacidad de degradar hidrocarburos de la playa de Caleta Córdova, Argentina
}

\author{
Diversity of culturable bacteria capable of degrading hydrocarbons from \\ the beach of Caleta Córdova, Argentina
}

\author{
Graciela N. Pucci, Adrián Acuña, Natalia Tonin, María C. Tiedemann y Oscar H. Pucci
}

Universidad Nacional de la $\mathrm{Pa}$ tagonia San Juan Bosco. Centro de Estudios e Investigación en Microbiología Aplicada (CEIMA) Facultad de Ciencias Naturales. Ruta Provincial $\mathrm{N}^{\circ} 14 \mathrm{~km}$ Comodoro Rivadavia (CP 9000), Chubut, Argentina.

Email Graciela Pucci: granapu@unpata.edu.ar

Presentado: 12/02/2010 Aceptado: $\quad$ 23/07/2010 Publicado online: $14 / 12 / 2010$

\section{Resumen}

En el presente trabajo se estudiaron las comunidades bacterianas aisladas de agua de mar y sedimentos intermareales de Caleta Córdova, norte de Comodoro Rivadavia, Argentina. Tres sitios fueron muestreados estacionalmente entre los años 2005 y 2006; el primer sitio fue una playa pública, el segundo sitio cerca de un puerto pesquero y el tercero cerca de una boya de toma de petróleo. Las comunidades bacterianas fueron determinadas en base a las diferencias en la composición de ácidos grasos de membrana, las bacterias fueron identificadas por medio del Sistema Sherlock MIDI, y el potencial de las comunidades para la utilización de hidrocarburos por la mineralización de gasoil, petróleo, kerosene, aceite lubricante y nafta. Las mineralizaciones evidenciaron la capacidad de los microorganismos para la degradación de hidrocarburos en dos de los sitios estudiados. Se aislaron 251 cepas de las que se lograron identificar 124 correspondientes a 24 géneros y 40 especies; la más frecuente fue Pseudoalteromonas.

Palabras claves: contaminación, biorremediación, bacterias marinas, FAME, Patagonia.

\section{Abstract}

Inter-tidal sediments and marine water from Caleta Córdova, a beach in the north of Comodoro Rivadavia, Argentina, were analyzed. Three sites were sampled each season between 2006 and 2006 . The first site is a public beach, the second site is near a fishing port and the third one near an oil buoy. Bacterial communities were determined based on differences in the composition of membrane fatty acids, identification of bacteria were using the MIDI Sherlock system, and the potential of communities for the use of hydrocarbons through the mineralization of gasoline, kerosene, diesel, crude oil and mineral oils. Mineralization showed a capacity of the microorganisms to use the hydrocarbons in only two sites of study. Of 251 strains were analyzed and the system could identify 24 genera and 40 species in only 124 strains. The rest of strains were not found in Sherlock data base (version 6.0). Pseudoalteromonas was the genus that was more frequently isolated.

Keywords: pollution, bioremediation, marine bacteria, petroleum contamination, FAME, Patagonia.

\section{Introducción}

Comodoro Rivadavia, conocida en Argentina como la capital del petróleo, es una ciudad donde se desarrolla una gran actividad petrolera; sin embargo no se cuenta con refinerías, por lo que el transporte de petróleo es intenso y la posibilidad de contaminación marino y costera es un riesgo permanente. Caleta Córdova se encuentra a unos $20 \mathrm{~km}$ al norte de la ciudad Comodoro Rivadavia en el Golfo San Jorge. Las playas de Caleta Córdova se caracterizan por ser utilizadas con diferentes fines. En la zona sur se realiza la carga de petróleo crudo en las embarcaciones de transporte por medio de una monoboya localizada a unos $4 \mathrm{~km}$ mar adentro. En el centro de la caleta se encuentra el puerto, donde se realizan actividades relacionadas con la pesca y extracción de mariscos. La zona norte es utilizada con fines recreativos durante la época de verano debido a su gran extensión y ausencia de actividad industrial.

La biorremediación es una técnica de recuperación de sitios impactados que utiliza tecnologías las cuales estimulan la biodegradación del contaminante por procesos biológicos, su objeto es minimizar las consecuencias de un derrame. Estos procesos de biodegradación pueden ser llevados a cabo por la microbiota autóctona de la zona contaminada o por microorganismos adicionados. En ambos casos, lo que se consigue es una biotransformación de sustancias peligrosas en sustancias menos toxicas o inocuas (Van Hamme et al. 2003). La selección de una determinada tecnología de biorremediación esta condicionada por múltiples factores, como por ejemplo, el tipo de microorganismos presentes en el medio, las condiciones del compartimiento contaminado (temperatura, oxigeno, energía, etc.), la concentración y la toxicidad de los contaminantes entre otros (Van Hamme et al. 2003).

Algunas bacterias marinas poseen capacidad de utilizar hidrocarburos como fuente de carbono y son la mejor opción en los derrames de petróleo en zonas costeras (Head y Swannell 1999). La biodegradación natural por parte de las bacterias nativas puede ser estimulada por el agregado de fertilizantes y oxígeno (Atlas 1991, Swalnnel 1996).

El presente trabajo, fue realizado entre el año 2005 y 2006, sirvió de línea de base para las tareas de recuperación de un impacto producido el 26 de diciembre del 2007. El propósito de nuestra investigación fue: (i) conocer la diversidad de la comunidad bacteriana cultivable con la utilización de los ácidos grasos de membranas bacterianas (FAMEs), y (ii) si la comunidad bacteriana es capaz de utilizar el petróleo y sus destilados, nafta, kerosene, gasoil y aceite lubricante como fuente de carbono y energía e (iii) identificar los miembros cultivables de la comunidad bacteriana determinadas por FAMEs.

\section{Material y métodos}

Toma de muestra.- Se tomaron tres muestras de agua de mar (M) del litoral de Caleta Córdova y tres muestras de sedimento (S) del área intermareal a una profundidad de 10 a $30 \mathrm{~cm}$. Los sitios de muestreo fueron tres. El primero ubicado en la zona norte (M1 y S1; 4544,384'S - 67 $\left.22,633^{\prime} \mathrm{W}\right)$, lugar que es utilizado para recreación en verano. El segundo en la zona del puerto (M2 y S2, $45^{\circ} 45,146^{\prime} \mathrm{S}-67^{\circ} 22,299^{\prime} \mathrm{W}$ ) y el tercero en 
la región sur (M3 y S3, 4545,651'S - 67²2,278’W) donde se ubica una monoboya de carga de petróleo. En cada sitio se tomaron muestras en las cuatro estaciones del año entre el año 2005 y 2006. Los parámetros abióticos de la zona fueron 1600 - $1700 \mathrm{mgL}^{-1}$ para cloruro, $2500-2700 \mathrm{mgL}^{-1}$ para sulfato, para bicarbonato $80-100 \mathrm{mgL}^{-1}$, para calcio $360-400 \mathrm{mgL}^{-1}$ y $1100-1200 \mathrm{mgL}^{-1}$ para magnesio. No se detectaron hidrocarburos totales de petróleo (EPA 418) en las muestras colectadas.

Recuentos bacterianos.- Se realizó el recuento en placa en medio para bacterias heterótrofas (BRN) (tripteína bacteriológica $5 \mathrm{~g}$, extracto de levadura $1 \mathrm{~g}, \mathrm{~K}_{2} \mathrm{HPO}_{4} 1 \mathrm{~g},\left(\mathrm{NH}_{4}\right)_{2} \mathrm{SO}_{4} 2 \mathrm{~g}$, agar-agar $15 \mathrm{~g}$, agua de mar estéril $700 \mathrm{~mL}$, agua destilada 300 $\mathrm{mL}, \mathrm{pH} 7,2$ ). La incubación se realizó a $28^{\circ} \mathrm{C}$ (Brown \& Leff 1996) durante 20 días en oscuridad. Para bacterias degradadoras de hidrocarburos $(\mathrm{BDH})$ se utilizó la técnica de diseminación en superficie en medio mineral con el agregado de $30 \mu \mathrm{L}$ de una mezcla 1:1 de petróleo gasoil (MM-PGO) por placa según lo propuesto por Pucci y Pucci en 2003, la temperatura de incubación fue de $28^{\circ} \mathrm{C}$ por 20 días.

Mineralización de hidrocarburos.- Se estudió mediante microcosmos, por triplicado, en frascos de vidrio de un litro de capacidad. Se utilizaron $50 \mathrm{~mL}$ de agua de mar o $5 \mathrm{~g}$ de sedimento en $45 \mathrm{~mL}$ de agua de mar estéril. Todos los microcosmos fueron inoculados con $50 \mathrm{~L}$ de una solución de nutrientes concentrada denominada $\mathrm{HDB}\left(\mathrm{K}_{2} \mathrm{HPO}_{4} 100 \mathrm{~g}\right.$, $\left(\mathrm{NH}_{4}\right)_{2} \mathrm{PO}_{4} 200 \mathrm{~g}$, agua destilada $1000 \mathrm{~mL}, \mathrm{pH}$ 7). Como fuente de carbono se utilizó nafta al 0,05\% y kerosén, gasoil, petróleo y aceite lubricante al $0,1 \%$. Se realizaron dos controles, uno con el agregado de los nutrientes y otro sin nutrientes.

El potencial de biodegradación se determinó por el dosaje del dióxido de carbono producido. Para ello se colocó un frasco colector, dentro del microcosmo, con hidróxido de sodio para la captura del $\mathrm{CO}_{2}$ producido por el sistema. Este se tituló con ácido clorhídrico valorado, utilizando fenolftaleina y heliantina como indicadores del punto final. En cada caso se realizó un control, que contenía la muestra y la solución concentrada de nutrientes para conocer la mineralización en las muestras sin el agregado de hidrocarburos. Los sistemas se incubaron a $28{ }^{\circ} \mathrm{C}$ en oscuridad durante 50 días (Pucci et al. 2009).

Los datos graficados representan los valores de mineralización del hidrocarburo ensayado, corregido por lo observado a partir del control diseñado. Con los datos de mineralización acumulada se obtuvo la tasa de mineralización de cada sistema expresada en miligramos de $\mathrm{CO}_{2}$ por kilogramo para sedimento o litro para agua de mar por día.

Estudio de la comunidad bacteriana.- A $100 \mathrm{~mL}$ de agua de mar se le adicionó $1 \mathrm{~mL}$ de una solución estéril 100 veces concentrada de caldo BRN (tripteína bacteriológica $50 \mathrm{~g}$, extracto de levadura $10 \mathrm{~g}, \mathrm{~K}_{2} \mathrm{HPO}_{4} 10 \mathrm{~g},\left(\mathrm{NH}_{4}\right)_{2} \mathrm{SO}_{4} 20 \mathrm{~g}$, agua de mar estéril $700 \mathrm{~mL}$, agua destilada $300 \mathrm{~mL}, \mathrm{pH}$ 7,2). El sedimento, $10 \mathrm{~g}$, se colocó en $90 \mathrm{~mL}$ de caldo BRN. Para conocer la comunidad degradadora de hidrocarburos se tomó $100 \mathrm{~mL}$ de agua de mar o $10 \mathrm{~g}$ de sedimento en $90 \mathrm{~mL}$ de agua de mar estéril, a los que se les colocó $100 \mu \mathrm{L}$ de HDB y hexadecano al $0,1 \%$ o fenantreno al $0,05 \%$. Los sistemas se realizaron por triplicado y se cultivaron 10 días a $28^{\circ} \mathrm{C}$ con agitación constante y oscuridad.

La extracción de ácidos grasos se realizó sobre el pellet resultante de la centrifugación a $4500 \mathrm{rpm}$ de los medios de cultivo, efectuando una saponificación con alcohol metílico-hidróxido de sodio-agua (150 mL: $45 \mathrm{~g}$ : $150 \mathrm{~mL}$ ) seguida de una metilación con ácido clorhídrico $6 \mathrm{~N}$ y alcohol metílico (325 mL: $275 \mathrm{~mL}$ ) y a continuación una extracción con n-hexano-metil térbutil éter (1:1) y lavado con hidróxido de sodio-agua $(10,8 \mathrm{~g}-900 \mathrm{~mL})$ de acuerdo con el procedimiento del sistema de identificación (MIDI Newark, Del., USA). Las muestras fueron almacenadas a $-20{ }^{\circ} \mathrm{C}$ hasta su análisis.

Los ácidos grasos se determinaron como metíl ésteres por cromatografía gaseosa usando una columna capilar Ultra 2 de 25 $\mathrm{m}$ de longitud, 0,2 $\mathrm{mm}$ de diámetro. El análisis se llevó a cabo con un cromatógrafo HP 6890 series II GC (inyección splitless; presión inicial $10 \mathrm{psi}$; programa de temperatura: $170-288^{\circ} \mathrm{C} \mathrm{a}$ $28^{\circ} \mathrm{C} / \mathrm{min}, 288-310^{\circ} \mathrm{C} 60^{\circ} \mathrm{C} / \mathrm{min}, 1,5 \mathrm{~min}$. de permanencia a $310^{\circ} \mathrm{C}$, detector por ionización de llama), la integración de los picos se efectuó mediante HP 10.01 Chem Station, los ácidos grasos fueron identificados utilizando Sherlock (versión 6.0) con el estándar Agilent Calibration standards kit for the microbial identification system. La composición en ácidos grasos fue calculada como porcentaje del área de pico (Pucci \& Pucci 2006).

Identificación de cepas aisladas.- A partir de los recuentos bacterianos realizados en agua de mar y en sedimentos, se aislaron 251 cepas para su posterior identificación por FAMEs. Se realizó un aislamiento por estrías en medio TSBA (tripteína 15 $\mathrm{g}$, peptona de soya $5 \mathrm{~g}$, cloruro de sodio $5 \mathrm{~g}$, agar $15 \mathrm{~g}$, glucosa 2,5 g, agua destilada $1000 \mathrm{~mL}, \mathrm{pH} 7$ ).

Los aislamientos se realizaron de todas las muestras de agua y sedimento. La extracción de ácidos grasos se realizó sobre 40 mg de bacterias (peso húmedo) crecidas en la tercera estría de la placa de TSBA cultivada a $28{ }^{\circ} \mathrm{C}$ durante $24 \mathrm{~h}$, de acuerdo con el procedimiento del sistema de identificación (MIDI Newark, Del., USA www.midi-inc.com), según lo publicado anteriormente (Pucci et al. 2009).

Análisis estadístico.- Los valores de mineralización y recuento se analizaron utilizando análisis de varianza (ANOVA) mediante el programa PAST. Para el análisis de los perfiles de FAMEs obtenidos se realizó un estudio de componentes principales utilizando el programa PAST.

\section{Resultados}

Recuentos bacterianos.- En los recuentos de bacterias no se presentaron diferencias significativas entre los tres puntos de toma de muestra de agua, en los dos medios de cultivo utilizados en cada estación ( $\mathrm{p}>0,05)$. Tampoco se presentaron diferencias significativas en las cuatro estaciones para cada punto (todos p> 0,05) siendo los valores hallados los que frecuentemente se observan en agua de mar (Stabili \& Cavallo 2004) (Tabla 1). En los sedimentos estudiados se observó un mayor número de microorganismos que en las muestras de agua de mar. El sedimento del punto de muestreo 2 fue el que mostró los valores de bacterias heterótrofas y degradadoras de hidrocarburos más elevados de los tres estudiados.

Mineralización.- Los sedimentos dan un soporte a la comunidad bacteriana (Stoeck et al. 2002) lo que implicó que los valores de mineralización fueran mayores a los de agua para los mismos puntos (Fig. 1). Los valores de las mineralizaciones más elevados, en sedimento, se obtuvieron en el sitio 2, seguido del sitio 3. En ambos se observó el mismo patrón estacional, con valores más elevados de mineralización en la estación de otoño. 
Tabla 1. Recuentos bacterianos en medio BRN y en MBM-PGO expresados $\times 10^{2}$ UFC. $\mathrm{mL}^{-1}$ y UFC. $\mathrm{g}^{-1}$ para las muestras de agua de mar y sedimento respectivamente.

\begin{tabular}{ccccc}
\hline & \multicolumn{4}{c}{ BRN } \\
\cline { 2 - 5 } & Primavera & Verano & Otoño & Invierno \\
\hline M-1 & $0,50 \pm, 065$ & $1,70 \pm 0,35$ & $5,00 \pm 1,00$ & $19,4 \pm 0,98$ \\
S-1 & $279 \pm 64$ & $360 \pm 44$ & $6,00 \pm 0,36$ & $193 \pm 50$ \\
M-2 & $8,90 \pm 0,89$ & $98,0 \pm 10,0$ & $3,20 \pm 1,20$ & $17,3 \pm 6,4$ \\
S-2 & $2250 \pm 520$ & $7300 \pm 150$ & $40,0 \pm 8,7$ & $410 \pm 88$ \\
M-3 & $5,50 \pm 0,69$ & $2,20 \pm 0,99$ & $3,20 \pm 0,65$ & $3,00 \pm 0,69$ \\
S-3 & $95,0 \pm 5,3$ & $400 \pm 74$ & $248 \pm 97$ & $1,40 \pm 0,94$ \\
\hline & & MBM-PGO & \\
\hline M-1 & $2,80 \pm 0.1$ & $0,4 \pm 0,02$ & $9,20 \pm 0,5$ & $6,60 \pm 0.6$ \\
S-1 & $1 \pm 0.01$ & $7,0 \pm 10$ & $163 \pm 6,6$ & $76,0 \pm 6,7$ \\
M-2 & $6,10 \pm 0.2$ & $20,9 \pm 0.1$ & $56,0 \pm 0.7$ & $0,60 \pm 0,040$ \\
S-2 & $202 \pm 13$ & $3210 \pm 120$ & $143 \pm 7$ & $205 \pm 10$ \\
M-3 & $294 \pm 9$ & $30,2 \pm 8$ & $3,60 \pm 0.1$ & $3,10 \pm 0.9$ \\
S-3 & $169 \pm 40$ & $540 \pm 20$ & $9,00 \pm 0.9$ & $10 \pm 0.54$ \\
\hline
\end{tabular}

Por último, el sitio 1 presentó su mayor valor en verano. El hidrocarburo menos mineralizado en sedimento fue la nafta y en agua de mar fue la nafta junto con el aceite lubricante. El sistema de control sin nutrientes presentó valores de mineralización en el orden de $60-90 \mathrm{mgCO}_{2}$ al cabo de los 50 días.

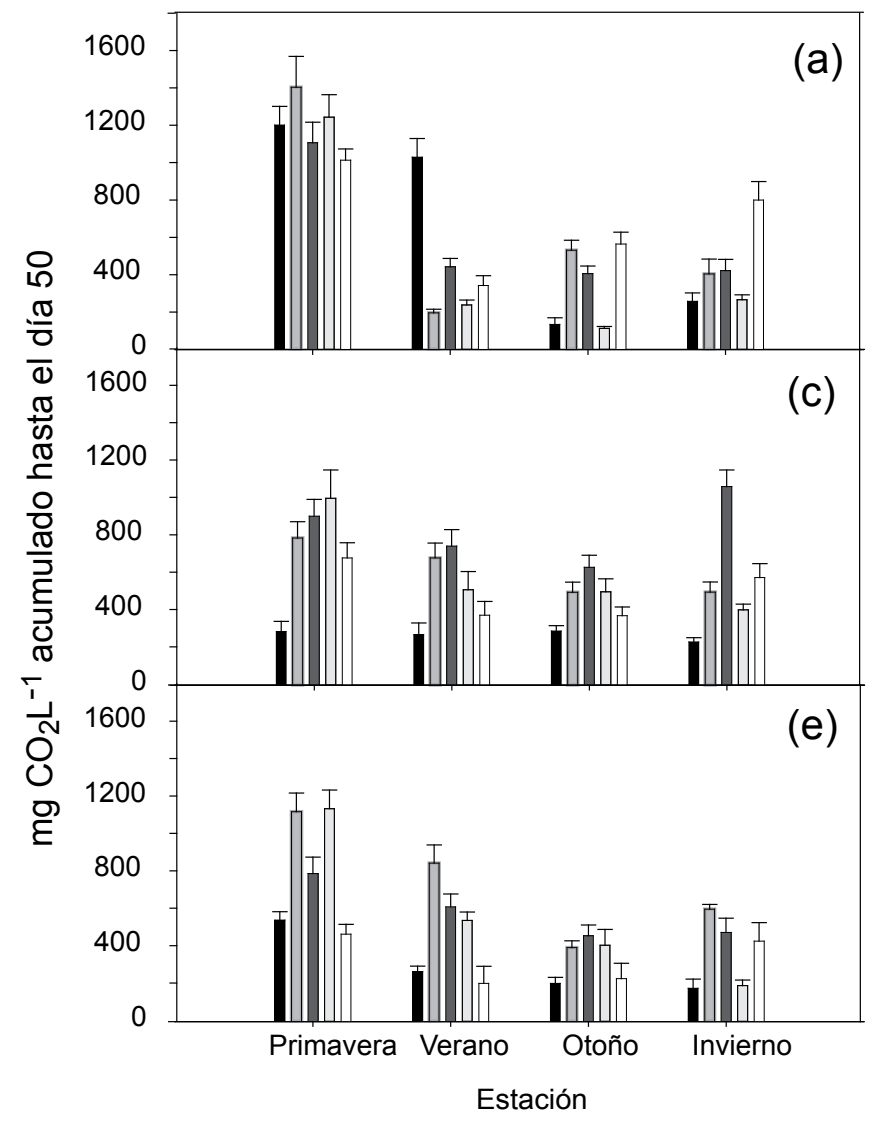

Nafta $\square$ Kerosene $\square$ Gas oil
En agua de mar, las mineralizaciones se presentaron de forma diferente al sedimento, los valores más elevados se presentaron en la primavera. Para el resto de las estaciones los valores de mineralización oscilaron entre 200 y $800 \mathrm{mgCO}_{2} \mathrm{~kg}^{-1}$ siendo la nafta y el aceite lubricante los menos utilizados en los sitio 2 y 3. En el sitio 1, el kerosén y la nafta poseen los menores valores de mineralización en otoño e invierno.

La tasa de mineralización para los primeros 14 días se encuentra en la Tabla 2 y muestra que el incremento de producción de $\mathrm{CO}_{2}$ es mayor de 0 a 14 días que de 15 a 50 días. Esto indica que la producción de $\mathrm{CO}_{2}$ a partir de los hidrocarburos ensayados se realiza principalmente en los primeros 14 días.

Estudio de las comunidades bacterianas.- Un total de 70 ácidos grasos se encontraron en las muestras de agua, del 9:0 al 20:0, encontrándose en mayor cantidad 16:1 $\omega 7$ c, seguido de los ácidos grasos 12:0 3OH y 10:0 3OH. Todos ellos son marcadores de ácidos grasos de bacterias Gram negativas (Frostegård et al 1993, Zelles 1997 y Konopka et al. 1999). En los sedimentos se hallaron un total de 68 ácidos grasos, siendo los mayoritarios el 16:1 $\omega$ 7c, 10:0 3OH, 16:0 y 18:1 $\omega$ 7c, también indicadores de bacterias Gram negativas. De los ácidos grasos saturados, el 16:0 fue, en ambos tipos de muestras, el que presentó los valores más elevados, mientras que de los ácidos grasos insaturados fue el 16:1 $\omega 7$ c. No se hallaron ácidos grasos trans, y en bajo porcentaje de observó ácidos grasos iso y anteiso que son los marcadores de bacterias Gram positivas (Frostegård et al. 1993, Zelles 1997). El hallazgo de estos ácidos grasos coincide con estudios realizados

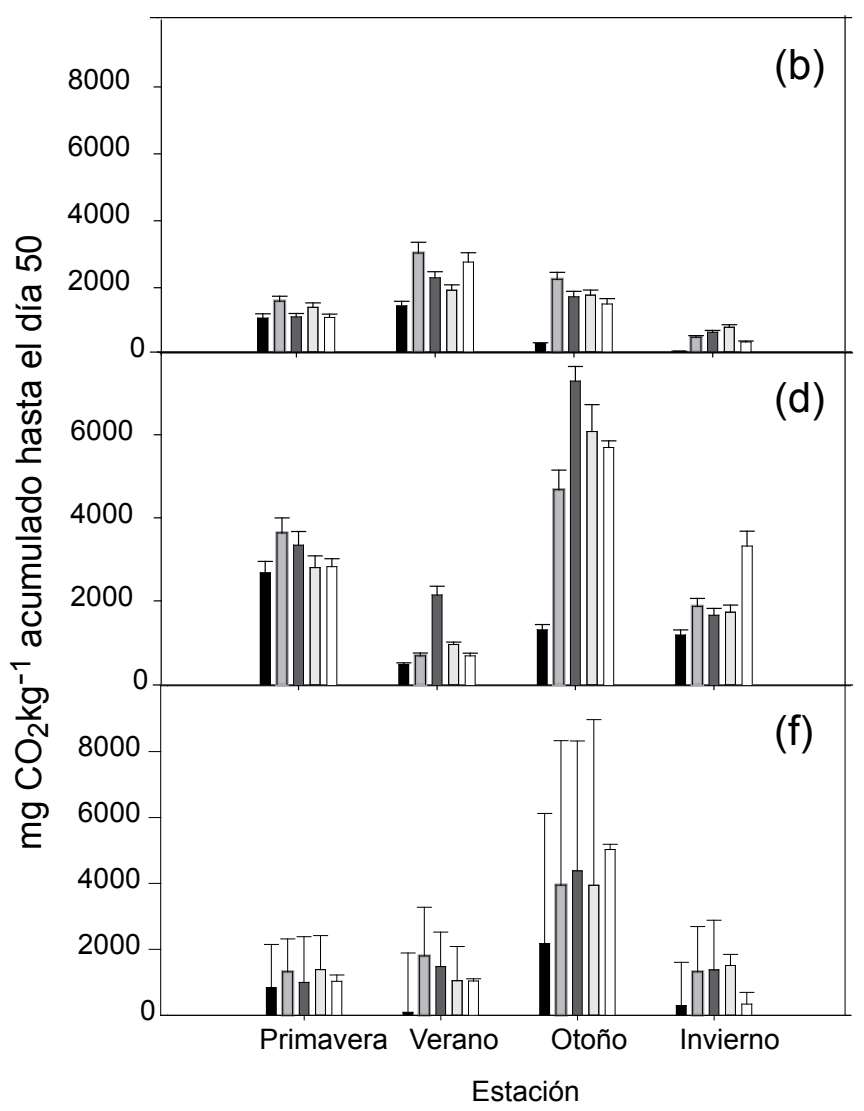

$\square$ Petróleo $\square$ Aceite lubricante

Figura 1. Valor del $\mathrm{CO}_{2}$ acumulado al día 50 de las mineralizaciones de las muestras de agua y sedimento de los tres sitios en todas las estaciones. Figuras (a), (c) y (e) muestras de agua de los sitio 1, 2 y 3 respectivamente. Figuras (b), (d) y (f) corresponden a las muestras de sedimento de los sitios 1,2 y 3 respectivamente. 
Tabla 2. Tasa de mineralización, expresada en $\mathrm{mgCO}_{2}$ por kg para sedimento o L para agua por día, en el día 14 de las muestras de agua y sedimento en las cuatro estaciones.

\begin{tabular}{|c|c|c|c|c|c|c|c|c|}
\hline \multirow[b]{2}{*}{ delta día } & \multicolumn{2}{|c|}{ Primavera } & \multicolumn{2}{|c|}{ Verano } & \multicolumn{2}{|c|}{ Otoño } & \multicolumn{2}{|c|}{ Invierno } \\
\hline & 14 & 56 & 14 & 56 & 14 & 56 & 14 & 56 \\
\hline Naf-M1 & 60,95 & 8,89 & 12,07 & 0,00 & 8,03 & 2,30 & 29,85 & 12,08 \\
\hline Ker-M1 & 68,64 & 11,01 & 9,70 & 5,51 & 10,73 & 11,14 & 43,02 & 11,50 \\
\hline GO-M1 & 49,72 & 10,67 & 19,47 & 8,11 & 18,76 & 5,53 & 43,02 & 11,92 \\
\hline Pet-M1 & 66,20 & 7,99 & 12,13 & 5,71 & 8,08 & 1,78 & 37,72 & 9,86 \\
\hline AL-M1 & 52,06 & 6,61 & 12,11 & 8,20 & 8,03 & 12,79 & 62,36 & 14,93 \\
\hline Naf-M2 & 9,65 & 4,40 & 19,42 & 4,03 & 5,36 & 6,94 & 24,55 & 13,10 \\
\hline Ker-M2 & 23,69 & 13,37 & 24,31 & 12,18 & 10,78 & 10,29 & 40,46 & 14,54 \\
\hline GO-M2 & 44,95 & 6,57 & 34,03 & 10,46 & 32,18 & 6,76 & 59,53 & 22,08 \\
\hline Pet-M2 & 78,09 & 18,51 & 26,75 & 7,31 & 29,51 & 9,29 & 45,76 & 10,64 \\
\hline AL-M2 & 28,76 & 7,03 & 19,44 & 6,51 & 13,39 & 6,41 & 35,07 & 18,05 \\
\hline Naf-M3 & 26,62 & 4,44 & 17,00 & 4,77 & 5,36 & 4,85 & 40,11 & 7,02 \\
\hline Ker-M3 & 48,56 & 11,48 & 31,62 & 13,69 & 18,86 & 5,25 & 45,84 & 15,31 \\
\hline GO-M3 & 28,96 & 10,58 & 29,19 & 8,95 & 10,71 & 9,36 & 32,16 & 16,59 \\
\hline Pet-M3 & 63,96 & 5,29 & 34,06 & 5,59 & 18,81 & 5,57 & 34,81 & 9,00 \\
\hline AL-M3 & 7,22 & 10,65 & 7,26 & 6,51 & 40,30 & 8,45 & 26,86 & 17,12 \\
\hline Naf-S1 & 48,76 & 6,92 & 116,85 & 12,99 & 0,00 & 7,88 & 30,73 & 10,15 \\
\hline Ker-S1 & 49,33 & 20,90 & 175,27 & 31,09 & 96,99 & 23,98 & 73,62 & 6,77 \\
\hline GO-S1 & 49,62 & 9,35 & 131,42 & 28,14 & 91,60 & 13,06 & 79,91 & 8,46 \\
\hline Pet-S1 & 55,88 & 14,98 & 141,21 & 15,93 & 96,99 & 12,47 & 91,24 & 8,46 \\
\hline AL-S1 & 51,96 & 8,04 & 160,70 & 29,48 & 75,44 & 12,81 & 62,69 & 6,77 \\
\hline Naf-S2 & 127,84 & 22,95 & 38,88 & 17,78 & 355,63 & 158,08 & 82,12 & 22,29 \\
\hline Ker-S2 & 201,05 & 16,72 & 38,88 & 22,70 & 204,76 & 51,49 & 114,97 & 28,56 \\
\hline GO-S2 & 174,14 & 23,11 & 107,05 & 34,89 & 447,23 & 38,44 & 87,60 & 31,90 \\
\hline Pet-S2 & 150,15 & 17,77 & 72,94 & 17,90 & 328,69 & 46,43 & 104,02 & 28,58 \\
\hline AL-S2 & 149,37 & 17,70 & 0,00 & 0,00 & 344,85 & 31,88 & 164,25 & 47,83 \\
\hline Naf-S3 & 40,86 & 7,14 & 24,26 & 13,08 & 118,54 & 17,20 & 43,80 & 12,36 \\
\hline Ker-S3 & 59,38 & 12,32 & 97,31 & 29,45 & 204,76 & 33,16 & 87,60 & 23,29 \\
\hline GO-S3 & 49,72 & 8,04 & 77,86 & 28,18 & 242,12 & 31,77 & 82,12 & 26,35 \\
\hline Pet-S3 & 66,10 & 11,48 & 58,37 & 24,49 & 215,53 & 29,52 & 93,07 & 26,15 \\
\hline AL-S3 & 40,07 & 13,33 & 63,25 & 22,69 & 312,52 & 25,25 & 27,37 & 18,60 \\
\hline
\end{tabular}

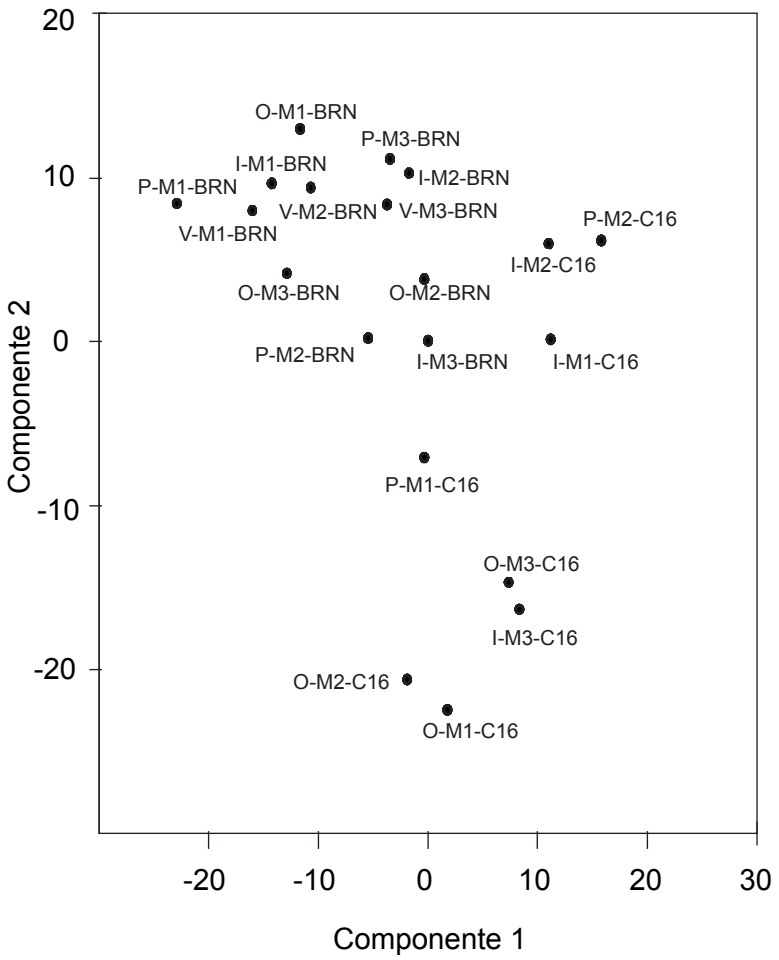

Figura 2. Análisis de PCA de FAME para las muestras de agua en los tres medios líquidos estudiados en las cuatro estaciones, BRN, C16: hexadecano y FEN: fenantreno, P: primavera, V: verano, O: otoño, I: invierno.

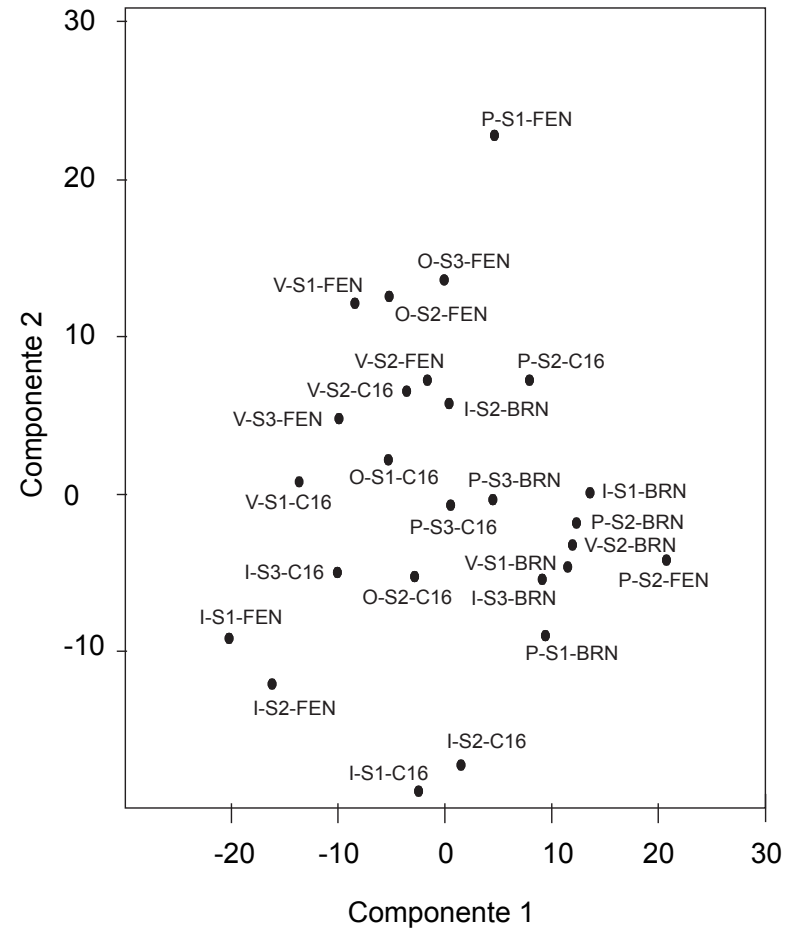

Figura 3. Análisis de PCA de FAME para las muestras de sedimento en los tres medios líquidos estudiados en las cuatro estaciones, BRN, C16: hexadecano, y FEN: fenantreno. P: primavera, V: verano, O: otoño, I: invierno. 
en el Mar del Norte (Stoeck et al. 2002), donde también son más abundantes las bacterias Gram negativas.

No se detectó la presencia de los ácidos grasos 10 metil, que son marcadores del grupo de los actinomices y corineformes (Atlas 2003). Todo esto se condice con las cepas aisladas e identificadas a partir de las muestras estudiadas (Tabla 3).

El análisis de ordenamiento muestra que la comunidad cultivada en BRN se agrupa en las muestras de agua (Fig. 2) y en las de sedimento (Fig. 3), teniendo dos excepciones en el sedimento que son la muestra de primavera del sitio 3 y de invierno en el sitio 2. En los dos tipos de muestras el crecimiento en presencia de hidrocarburos produjo una dispersión de las muestras, las que no presentaron ningún tipo de agrupamiento por sitio.

Identificación de cepas.- Se aislaron 251 cepas a partir de los diferentes sitios de toma de muestras. Se pudo identificar 124 cultivos, que pertenecieron a 24 géneros y 40 especies diferentes (Tabla 3). Los géneros bacterianos con mayor porcentaje de recuperación fueron Pseudoalteromenas, Bacillus, Psychrobactery Shenewanella, con un 21, 18, 13 y $6 \%$ respectivamente. Dentro de estos cuatro géneros mencionados, las especies más representativas fueron Pseudoalteromonas nigrifaciens, Bacillus atrophaeus, megaterium y pumilus, Psychrobacter immobilis y Shewanella putrefaciens. Estos microorganismos, a excepción de Bacillus, fueron los más recuperados a partir de las placas utilizadas para contar bacterias degradadoras de hidrocarburos. Las restantes 127 cepas no fueron identificadas porque su coeficiente de identificación fue menor al que el sistema sugiere.

Tabla 3. Taxa bacterianos encontrados en los aislamientos en todas las estaciones y sitios estudiados.

\begin{tabular}{ll}
\hline Acinetobacter sp & Paracoccus denitrificans \\
Acinetobacter lwoffii & Photobacterium sp \\
Aeromonas sp & Photobacterium angustum \\
Arthrobacter mysorens & Pseudoalteromonas sp \\
Bacillus sp & Pseudoalteromonas nigrifaciens \\
Bacillus atrophaeus & Pseudomonas sp \\
Bacillus megaterium & Pseudomonas putida \\
Bacillus pumilus & Psychrobacter immobilis \\
Brevibacillus choshinensis & Rhodobacter sp \\
Brevundimonas vesicularis & Rhodobacter capsulatus \\
Burkholderia cepacia & Rhodobacter sphaeroides \\
Halomonas aquamarina & Rhodococcus sp \\
Kocuria kristinae & Shewanella putrefaciens/algae \\
Kocuria varians & Sphingopyxis macrogoltabida \\
Kurthia gibsonii & Staphylococcus sp \\
Lysobacter enzymogenes enzymogenes & Staphylococcus hominis hominis \\
Microbacterium liquefaciens & Vibrio fischeri \\
Micrococcus luteus & \\
Micrococcus lylae & Vibria uliginosa \\
\hline
\end{tabular}

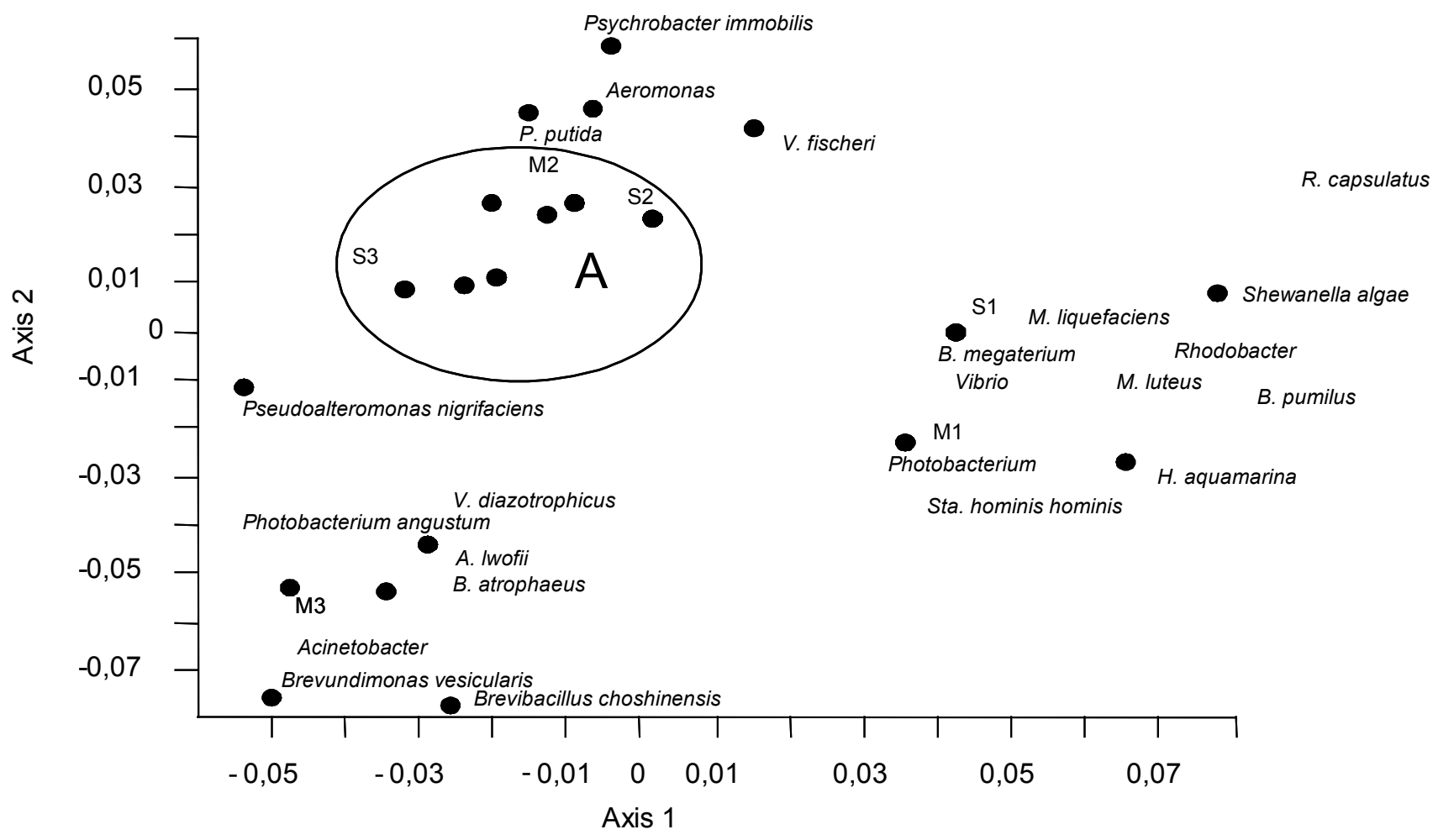

Figura 4. Análisis del Componnente Principal de FAME de las identificaciones bacterianas con los sitios. Grupo A: Burkholderia cepacia, L. enzymogenes, K. varians, K. kristinae, R. sphaeroides, O. anthropi, Rhodococcus, M. Iylae, S.macroltabida, Pseudomonas, Z. uliginosa, Paracoccus denitrificans, Arthrobacter mysorens, Pseudoalteromonas, K. gibs, Bacillus, Onii, Bacillus, B. pumilus, Sta. hominis, R. capsulatus. (A) Acinetobacter, (B) Bacillus, (H) Halomonas, (K) Kocuria, (L) Lisobacter, (M) Micrococcus, (O) Ochrobactrum, (P) Pseudomonas, (R) Rodobacter, (S) Sphingopyxis, (Sta) Staphylococcus, (V) Vibrios, (Z) Zobelia. 
Las especies bacterianas identificadas se agruparon en función a los sitios de muestreo (Fig. 4), observándose que los sitios donde puede encontrarse pequeñas contaminaciones accidentales, sitio 2 y 3, se ubicaron más próximos entre sí, a excepción de la muestra M3. Los sedimentos de los sitios 2 y 3 estuvieron asociados a grupos bacterianos con capacidad de utilizar hidrocarburos (Pseudomonas, Rhodococcus, Bacillus) mostrando que los microorganismos que desarrollan a partir de estos, son de similares características. El sitio de muestreo 1, ubicado en el área recreacional de Caleta Córdova, se encontró más alejado en el análisis de componentes principales realizado. La proximidad observada entre las muestras M1 y S1 señala que los integrantes de la comunidad bacteriana de ambos son similares, siendo estos muy diferentes a los microorganismos de los demás puntos de toma de muestras, influenciado esto, por la ausencia de contaminantes en las cercanías del sitio 1 .

\section{Discusión}

Durante muchos años, el transporte de petróleo se ha realizado utilizando embarcaciones de gran tamaño para distribuirlo hacia diferentes lugares del mundo. Si bien los accidentes de buques petroleros no son tan frecuentes, cuando ocurren y su contenido es derramado, causan un gran impacto en el medio ambiente, sobre todo en las costas cercanas como las ocurridas en 1978 en Francia, en 1989 en Alaska, en 1990 en las costas de Texas y California (Swalnnel et al. 1996) y en 2002 en Galicia (Vega et al. 2009).

Los derrames mas reconocidos fueron el de la costa de Alaska en 1998, en el que se vio involucrado el buque tanque Exxon Valdez y el ocurrido en la costa de Galicia en 2002 por la ruptura del buque tanque Prestige. En ambas experiencia se demostró la importancia del papel de los microorganismos para biorremediar los hidrocarburos derramados, tanto en el agua de mar como en los sedimentos intermareales (Bragg et al. 1994, Vega et al. 2009, Wright et al. 1997)

Uno de los factores que limitan la biodegradación de hidrocarburos derramados en ambientes marinos, es la escasa cantidad de nitrógeno y fósforo que se encuentra en los mismos (Head \& Swannell 1999). Por este motivo, la mineralización determinada por acumulación de $\mathrm{CO}_{2}$ se llevó a cabo con una fertilización con nitrógeno y fósforo, para que actúe positivamente sobre la biodegradación de los compuestos contaminantes. Los rangos de los recuentos bacterianos observados en agua de $\operatorname{mar}\left(10^{1}\right.$ a $10^{3}$ UFC $\mathrm{mL}^{-1}$ ) coinciden con los encontrados por Zweifel y Hagsrtöm en 1995 para el Mar Báltico, Mar del Norte y Mediterráneo.

La buena mineralización de los hidrocarburos en los sedimentos intermareales se debe a que estos proporcionan un mejor soporte para los hidrocarburos y los microorganismos, favoreciendo así, un mayor desarrollo de bacterias en su matriz, lo que se refleja en una utilización mas eficiente de los hidrocarburos como fuente de carbono (Stoeck et al. 2002). En nuestro trabajo, las mineralizaciones obtenidas en sedimentos fueron similares a lo observado en otros sistemas de biorremediación como el de landfarming (Riis et al. 2002), indicando la capacidad de la comunidad bacteriana para mineralizar hidrocarburos. Los valores en agua de mar fueron menores, influenciados por la hidrofobicidad de los hidrocarburos, que limita la utilización de estos últimos por parte de las bacterias, el sedimento da un soporte que permite un mejor contacto entre la bacteria y el hidrocarburo.
La mineralización de los hidrocarburos destilados del petróleo estudiados en medio líquido favorece a los microorganismos de rápido desarrollo como Pseudomonas (Atlas 2003). Los valores más elevados observados en el punto 2 están relacionados con la actividad en las cercanías del lugar de muestreo, esta es la zona del puerto y es donde se pueden producir microderrames de combustibles debido al gran movimiento de barcos en el lugar, lo que con el tiempo, conduce a un aumento de la comunidad bacteriana con capacidad de utilizarlos como fuente de carbono. Una situación similar ocurre en el punto 3, ubicado en la base del oleoducto que conduce el petróleo a la monoboya de carga, lugar donde se observaron valores de utilización de hidrocarburos similares a los del punto 2 . El punto 1 se encuentra en la playa utilizada con fines recreativos, algo alejada de los otros dos, lo que explica los valores más bajos de mineralización.

La comunidad bacteriana presente en el agua y en el sedimento que desarrolló en medio BRN no presentó cambio en las diferentes estaciones del ańo, siendo esto coincidente con lo observado por otros autores en el lago Kojima (Rajendran et al. 1995). Los medios de cultivo con hidrocarburos seleccionaron a una parte de la comunidad que toleró la presencia de estos y fue capaz de utilizarlos como fuente de carbono y energía.

Este ensayo, que se llevó a cabo en un medio líquido, seleccionó los microorganismos que se adaptan más rápidamente a las nuevas condiciones de cultivo, estos son, generalmente, Gram negativos (Atlas 2003). Esta es la razón por la cual se observaron ácidos grasos que marcan su presencia y no ácidos grasos como los 10 metil; aunque más tarde en los aislamientos de los recuentos se recuperaron cepas Gram positivas.

Las identificaciones realizadas coinciden con géneros bacterianos hallados frecuentemente en agua y sedimento marino (Stabili \& Cavallo 2004). Se observó cepas con capacidad de degradar hidrocarburos como Pseudomonas sp., que poseen una capacidad excelente de desarrollo en medios líquidos y de crecimiento rápido. Su capacidad de utilizar hidrocarburos es ampliamente conocida y se las encuentra con frecuencia en suelos patagónicos de la zona que poseen este tipo de contaminantes (Röling et al. 2002). Algunos géneros hallados en el presente trabajo han sido mencionados para el mar Mediterráneo (Stabili \& Cavallo 2004, Süss et al. 2004), por ejemplo Acinetobacter, productor de biosurfactantes que aumentan la biodisponibilidad de los productos insolubles en agua (Balde et al. 1999, Mohamed et al. 2005, Ron et al. 2002, Toren et al. 2001). Pseudoalteromnas, que posee la capacidad de utilizar hidrocarburos (Melcher et al. 2002) fue la más abundante en las identificaciones; está relacionada con Alteromonas y Shewanella, todas ellas Gammaprotobacterias hetorotróficas marinas (Ivanova et al. 2004). Röling et al. (2002) también encontraron en sedimentos marinos una mayoría de Gammaprotobacterias que se mantuvo constante luego de estar 26 días en un microcosmo con hidrocarburos. Shewanella ha sido estudiada en la última década en los procesos de biorremediación por poseer un importante rol en el cometabolismo de compuestos halogenados y del petróleo, también por su capacidad de reducir el magnesio y el óxido de hierro, como por su habilidad de producir ácidos grasos poliinsaturados (Ron et al. 2002), situación poco común en bacterias. Otro género encontrado fue Rhodococcus, que posee la capacidad de utilizar diversos hidrocarburos por su enorme versatilidad catabólica (Larkin et al. 1999, Ruberto et al. 2005, Seto et al. 1995, Whyte et al. 1999). 
En el Mar Adriático, Stabili et al. (2004) pudieron identificar un alto porcentaje géneros utilizando el sistema API 20, sin embargo éste cuenta con pocas reacciones, por ello es menos exacto que FAMEs el cual usa 135 caracteres; esto nos permite considerar que los datos obtenidos en el presente estudio son confiables. En la zona de Puerto Madryn, Chubut, Dionisi y Ferrero (2008) aislaron, con métodos moleculares 8 géneros bacterianos con capacidad de biodegradar hidrocarburos poliaromáticos. Esta ciudad se caracteriza por la gran actividad portuaria que posee, siendo esto un punto en común con el sitio 2 estudiado en este trabajo. Esto podría indicar que este tipo de costas, con gran actividad portuaria, posean microorganismos que hayan estado en contacto con hidrocarburos provenientes de microderrames ocasionados por los barcos que circulan.

Uno de los factores de suma importancia en la recuperación de ambientes marinos contaminados con hidrocarburos, es la presencia de microorganismos con capacidad de utilizarlos como fuente de carbono y energía (Head et al. 2006, Swalnnel et al. 1996); condiciones observadas en el litoral de Caleta Córdova, en particular en los puntos 2 y 3 , donde la ocurrencia de un posible derrame de hidrocarburos, podría metabolizarse y llevar adelante la biorremediación del lugar.

\section{Agradecimientos}

A PNUD ARG/02/018 - Donación GEF N² 28.385-AR por el financiamiento y al personal técnico del laboratorio CEIMA.

\section{Literatura citada}

Atlas R., R. Bartha. 2003. Ecología fisiológica de los microorganismos: adaptaciones a las condiciones ambientales. En: Capella I, editor. Ecología microbiana y microbiología ambiental Addison Wesley Press, p. 279-327.

Atlas R. 1991. Microbial hydrocarbon degradation-bioremediation of oil spills. Chem Technol Biotechnol 52: 149-156.

Balde F., N. Ivosevic, A. Minacci, et al. 1999. Ahesion of Acinetobacter venetianus to diesel oil fuel droplets studied with in situ electrochemical and molecular probes. Appl Environ Microbiol 65: 2041-2048.

Brown B.J. \& L.G. Leff. 1996. Comparison of Fatty Acid Methyl Ester Analysis with the Use of API 20E and NFT Strips for dentification of Aquatic Bacteria Appl. Envir. Microbiol., 62: 2183 - 2185 .

Bragg J., R. Prince, E. Harner, et al. 1994. Effectiveness of bioremediation for the Exxon Valdez oil spill. Nature 368: 413-418.

Dionisi H. \& M. Ferrero. 2008. BC-28 Potencial de biorremediación Intrínseca de hidrocarburos aromáticos policíclicos en sedimentos marinos de la costa patagónica. Plenario de Avances de subproyectos competitivos de Innovación Tecnológica e Investigación Aplicada. Ciudad de Buenos Aires 2007 libro de resumenes p 68-69. <http://www.ambiente. gov.ar/archivos/web/PCCGDBM/File/spc/ResumenSPC. pdf> (acceso 12/02/2010)

Frostegård Å., E. Bååth \& A. Tunlid. 1993. Shifts in the structure of soil microbial communities in limed forests as revealed by phospholipid fatty acid analysis. Soil Biol Biochem 25:723-730

Head I., D. Jones \& W. Röling. 2006. Marine Microorganisms Make a Meal of Oil. Nature Reviews. 4: 173-182.

Head I. \& R. Swannell. 1999. Bioremediation of petroleum hydrocarbon contaminants in marine habitats. Curr Opin Biotechnol 10: 234-239.
Ivanova E., S. Flavier \& R. Christen. 2004. Phylogenetic relationships among marine Alteromonas-like proteobacteria: emended escription of the family Alteromonadaceae and proposal of Pseudoalteromonadaceae fam. nov., Colwelliaceae fam. nov., Shewanellaceae fam. nov., Moritellaceae fam. nov., Ferrimonadaceae fam. nov., Idiomarinaceae fam. nov. and Psychromonadaceae fam. nov. Int J Syst Evol Microbiol 54: 1773-1788.

Konopka A., T. Zakharova, M. Bischoff et al. 1999. Microbial biomass and activity in lead-contaminated soil. Appl Environ Microbiol 65:2256-2259

Larkin M.,C. Allen,L. Kukalov et al. 1998. Purification and characterization of a novel naphtalene dioxygenase from Rhodococcus sp. strain NICMB12038. J Bacteriol 181: 6200-6204.

Melcher R., S. Apitz \& B. Hemmingsen.2002.Impact of irradiation and polycyclic aromatic hydrocarbons spiking on microbial populations in marine sediment for future aging and biodegradability studies. Appl Environ Microbiol 68: 2858-2868.

Mohamed A., E. Shenawy \& A. Farag. 2005. Spatial and temporal variability of saprophytic and water quality bacteria along the coast of Aqaba, Suez gulfs and red sea-egypt. Egypt J Aquat Res 31: 157-162.

Pucci G.N.,A.J. Acuña,M. Llanes et al. 2009. Identificación de bacterias marinas cultivables de la ciudad costera Comodoro Rivadavia, Argentina. Rev Biol Mar Oceanogr 44: 49-58.

Pucci G.N. \& O.H. Pucci. 2003. Biodegradabilidad de componentes de mezclas naturales de hidrocarburo previamente sometidas a Landfarming. Rev Argent Microbiol 35: 62-68.

Pucci G.N. \& O.H. Pucci. 2006. Cambios en los ácidos grasos de membrana de Microbacterium esteraromaticum GNP-5 con diferentes temperaturas y osmolaridades. Acta Biol Colomb 11: 61-73.

Rajendran N., O. Matsuda, N. Imamura, et al. 1995. Microbial community analysis of euxinic sediments using phospholipid fatty acid biomarkers. J Oceanog 51: 21-38.

Riis V., W. Babel \& O. Pucci. 2002. Influence of heavy metals on the microbial degradation of diesel fuel. Chemosphere 49: 559-568.

Röling W., M. Milner, D. Jones, al et. 2002. Robust hydrocarbon degradation and dynamics of bacterial communities during nutrient-enhanced oil spill bioremediation. Appl Environ Microbiol 11: 5537-5548.

Ron E.,E Zand \& E.Rosenberg. 2002 . Biosurfactants and oil bioremediation. Curr Opin Biotechnol 2002; 13: 249-252.

Ruberto L., S. Vazquez, A. Lobaldo, al et. 2005. Psychrotolerant hydrocarbon-degrading Rhodococcus strains isolated from polluted Antarctic soils. Antartic Soils 2005; 17: 47-56.

Seto M., K. Kimbara, M. Shimura, et al. 1995. A novel transformation of polychlorinated biphenyls by Rhodococcus sp. strain RHA1, Appl Environ Microbiol 61: 3353-3358.

Stabili L. \& R. Cavallo. 2004. Biodiversity of culturable heterotrophic bacteria in the Southern Adriatic Sea Italian coastal waters. Scient Mar 68: 31-41.

Stoeck T., I. Kröncke, G. Duineveld, et al. 2002. Phospholipid fatty acid profiles at depositional and non-depositional sites in the north sea. Mar Ecol Prog Ser 241: 57-70.

Süss J., S. Encelen, H. Cypionka et al.2004. Quantitative analysis of bacterial communities from Mediterranean sapropels based on cultivation depend methods. Microbiol Ecol 51: 109-121.

Swalnnel R., K. Lee, M. McDonagh. 1996. Field Evaluation of Marine Oil Spill Bioremediation. Microbiol Review 60: 342-365.

Toren F., S. Navon Venezia, E. Ron, et al. 2001. Emulsifying activities of purified Alasan proteins from cinetobacter radioresistens KA53. Appl Environ Microbiol 67: 1102-1106. 
Van Hamme J., A. Singh \& O. Ward. 2003. Recent advances in petroleum microbiology. Microbiol Mol Biol Reviews 67: 503-549.

Vega F., E. Covelo, M. Reigosa, et al. 2009. Degradation of fuel oil in salt marsh soils affected by the Prestige oil spill. J Hazar Mater 2009; 166: 1020-1029.

Whyte L., S. Slagman, F. Pietrantonio et al.1999. Physiological adaptation involved in alkane assimilation at a low temperature by a Rhodococcus sp. Strain Q15. Appl Environ Microbiol 65: 2961-2968.
Wright A., R. Weaver \& J. Webb. 1997. Oil bioremediation in salt marsh mesocosms as influenced by $\mathrm{N}$ and $\mathrm{P}$ fertilization, flooding, and season. Water Air Soil Pollut 95: 179-191.

Zelles L. 1997. Phospholipid fatty acid profiles in selected members of soil microbial communities. Chemosphere 35: 275-294

Zweifel A. \& A Hagström. 1995. Total count of marine bacterial include a large fraction of non-nucleoid-containing bacteria (Ghosts). Appl Environ Microbiol 1995; 61: 2180-2185. 